\title{
HHi-FiVe: A high-fidelity genetic engineering pipeline for construction of herpesvirus-based vaccines
}

Michael Jarvis ( $\triangle$ michael.jarvis@plymouth.ac.uk)

University of Plymouth https://orcid.org/0000-0002-0124-4061

Thekla Mauch

The Vaccine Group Ltd

Eleonore Ostermann

Heinrich Pette Institute

Yvonne Wezel

The Vaccine Group Ltd

Jenna Nichols

MRC-University of Glasgow Centre for Virus Research

Ana da Silva Filipe

MRC-University of Glasgow Centre for Virus Research

Matej Vucak

MRC-University of Glasgow Centre for Virus Research

Joseph Hughes

MRC-University of Glasgow Centre for Virus Research

Summer Henderson

The Vaccine Group Ltd

Kimberli Schmidt

UC Davis

Amitinder Kaur

University of California at Davis

Hester Nichols

The Vaccine Group Ltd

Robin Antrobus

University of Cambridge

Peter Barry

UC Davis

Andrew Davison

MRC-University of Glasgow Centre for Virus Research

Wolfram Brune

Heinrich Pette Institute

Article

Keywords:

Posted Date: October 28th, 2021

DOl: https://doi.org/10.21203/rs.3.rs-993639/v1

License: (a) (1) This work is licensed under a Creative Commons Attribution 4.0 International License. Read Full License 


\section{Abstract}

Herpesvirus-based vectors are attractive for use both as conventional and as transmissible vaccines against emerging zoonoses in hard-to-reach animal populations. However, the threat of off-site mutations during genetic manipulation of vector genomes poses a significant challenge to vaccine construction. Herein, we present the HHi-FiVe (herpesvirus high-fidelity vector) construction pipeline for generating herpesvirus-based vectors by modifying bacterial artificial chromosomes (BACs) and monitoring integrity at each stage by complete genome sequencing. We used this pipeline to repair a highly mutated rhesus cytomegalovirus BAC containing an Ebola virus transgene. The vector derived from this BAC had been shown previously to protect rhesus macaques from lethal Ebola virus challenge by conventional vaccination. Repair of this BAC restored wild-type cellular tropism to the vector, which is essential for transmissible vaccination. Construction of this candidate transmissible vaccine against Ebola virus demonstrates the utility of the HHi-FiVe pipeline for creating precision-made herpesvirus-based vectors.

\section{Introduction}

Herpesvirus-based vectors show considerable promise for use as vaccines against infectious diseases. Several such vaccines have been approved for commercial use in agricultural animals, in which they are highly effective. These include a live vaccine based on bovine herpesvirus 1 (Bovilis ${ }^{\circledR}$ IBR Marker Live) to combat infectious bovine rhinotracheitis in cattle ${ }^{1}$ and a live recombinant vaccine (VAXXITEK@ HVT+IBD) based on turkey herpesvirus to counter infectious bursal disease virus in chickens ${ }^{2}$. Experimental herpesvirusbased vaccines have similarly shown an ability to produce substantial levels of immunity with protection against a range of targeted pathogens, including viruses such as simian immunodeficiency virus ${ }^{3,4}$ and Ebola virus (EBOV) ${ }^{5-7}$, bacteria such as Mycobacterium tuberculosis ${ }^{8,9}$, and protozoa (Plasmodium knowlesi) ${ }^{10}$.

Herpesvirus-based vectors have several key features that have encouraged their development as vaccines ${ }^{11}$. These include an inherently low pathogenic potential, an ability to induce durable levels of antibody-based and T cell-mediated immunity, and a potential for administration via mucosal (i.e. oral and nasal) routes ${ }^{11}$. The vaccines are also amenable to reuse, as prior vector-specific immunity does not prevent reinfection $3,5,11,12$. These features, combined with high host species restriction and the ability to spread among individuals, have motivated the development of transmissible herpesvirus-based vaccines for targeting emerging zoonotic pathogens in the inaccessible wildlife animal populations from which they frequently arise ${ }^{13,14}$. Advances in bacterial artificial chromosome (BAC)-based genetic engineering have played a large part in the development of technology for manipulating the vectors ${ }^{15}$. Nonetheless, compared to other vaccine modalities, the large genome sizes of herpesviruses and the potential for off-site mutation during manipulation present significant challenges to the widespread use of herpesvirus-based vectors as vaccines, especially in emerging zoonotic disease scenarios, where it is critical to respond rapidly while ensuring the accuracy of vaccine construction.

We have established a robust approach for iterative, high-fidelity genetic engineering of herpesvirus-based vectors. This approach was named the HHi-FiVe (herpesvirus high-fidelity vector) pipeline and was used to restore a total of 13 mutated or missing open-reading frames (ORFs) in a BAC containing a cytomegalovirus (CMV) genome from rhesus CMV (RhCMV) bearing a transgene expressing an EBOV antigen. This BAC (RhCMV68-1/EBOV BAC) was chosen as a starting point because the vector derived from it by transfection has been shown to protect rhesus macaques that were vaccinated subcutaneously and then challenged with normally lethal EBOV doses $^{5}$. As anticipated, the vector reconstituted from the repaired BAC exhibited a phenotype characterized by restored epithelial cell tropism and sustained expression of the transgene (EBOV-GP). This work generated a repaired vector suitable for future model studies of animal-to-animal transmission and demonstrated the practicality of the HHi-FiVe pipeline for producing herpesvirus-based vectors for potential use as vaccines.

\section{Results}

\section{RhCMV BACs and ORF nomenclature}

Following isolation from the urine of a rhesus macaque in 1968 , a parental virus ( $R h C M V$ strain $\left.68-1 ; \operatorname{RhCMV}_{68-1}\right)$ was subjected to extensive and largely undocumented passage in cultured fibroblasts of human or rhesus macaque origin ${ }^{16}$. A stock of the resulting virus was used to construct a primary $B A C\left(\mathrm{RhCMV}_{68-1} \mathrm{BAC}\right)^{17}$, from which all available RhCMV BACs are derived. A succession of 
studies has shown that $\mathrm{RhCMV}_{68-1}$ and $\mathrm{RhCMV}_{68-1} \mathrm{BAC}$ are highly mutated ${ }^{18-23}$, with the detail having been revealed progressively by the genome sequences of $\mathrm{RhCMV}_{68-1}, \mathrm{RhCMV}_{68-1} \mathrm{BAC}$, derivatives of $\mathrm{RhCMV}_{68-1} \mathrm{BAC}$, viruses generated from $\mathrm{RhCMV}_{68-1}$-based BACs, and other RhCMV strains (Table 1). As a result, RhCMV $\mathrm{R}_{68-1}$ and $\mathrm{RhCMV}_{68-1} \mathrm{BAC}$ lack the functions of many genes required for cellular tropism and fitness in vivo. It was necessary to repair these mutations in order to create a candidate for testing as a transmissible vaccine. Achieving this involved making multiple small- and large-scale repairs to $\mathrm{RhCMV}_{68-1} / \mathrm{EBOV}$ BAC and carrying out Illumina-based complete genome sequencing at each stage to monitor fidelity. 
Table 1

RhCMV genome sequences ${ }^{\mathrm{a}}$.

\begin{tabular}{|c|c|c|c|}
\hline GenBank accession no. & Parental strain & Source of sequence & Reference \\
\hline AY186194.1 & $68-1$ & Isolated virus & Hansen et al., $2003^{24}$ \\
\hline JQ795930.1 & $68-1$ & BAC & Malouli et al., $2012^{20}$ \\
\hline MF468139.1 & $68-1$ & BAC-derived virus & Hansen et al., $2018^{8}$ \\
\hline MF468140.1 & $68-1$ & BAC & Hansen et al., 2018 \\
\hline MF468141.1 & $68-1$ & BAC-derived virus & Hansen et al., 2018 \\
\hline MF468142.1 & $68-1$ & BAC-derived virus & Hansen et al., 2018 \\
\hline MF468143.1 & $68-1$ & BAC-derived virus & Hansen et al., 2018 \\
\hline MF468144.1 & $68-1$ & BAC-derived virus & Hansen et al., 2018 \\
\hline MF468145.1 & $68-1$ & BAC-derived virus & Hansen et al., 2018 \\
\hline MF468146.1 & $68-1$ & BAC-derived virus & Hansen et al., 2018 \\
\hline MF468147.1 & $68-1$ & BAC & Hansen et al., 2018 \\
\hline MK937070.1 & $68-1$ & BAC & Marshall et al., $2019^{42}$ \\
\hline MN437483.1 & $68-1$ & BAC & Hansen et al., $2009^{4}$ \\
\hline MT157325.1 & $68-1$ & BAC & Taher et al., $2020^{23}$ \\
\hline MT157326.1 & $68-1$ & BAC & Taher et al., 2020 \\
\hline MT157327.1 & $68-1$ & BAC & Taher et al., 2020 \\
\hline$M Z 517252.1^{b}$ & $68-1$ & BAC & Present study \\
\hline MZ517253.1 ${ }^{\mathrm{c}}$ & $68-1$ & BAC & Present study \\
\hline DQ120516.1 & 180.92 & Isolated virus & Rivailler et al., $2006^{18}$ \\
\hline KX689267.1 & 19262 & Isolated virus & Burwitz et al., $2016^{21}$ \\
\hline KX689268.1 & 19936 & Isolated virus & Burwitz et al., 2016 \\
\hline KX689269.1 & 24514 & Isolated virus & Burwitz et al., 2016 \\
\hline MT157328.1 & 34844 & Isolated virus & Taher et al., 2020 \\
\hline MT157329.1 & KF03 & Isolated virus & Taher et al., 2020 \\
\hline MT157330.1 & UCD52 & Isolated virus & Taher et al., 2020 \\
\hline MT157331.1 & UCD59 & Isolated virus & Taher et al., 2020 \\
\hline MZ517254.1 $1^{d}$ & 180.92 & Isolated virus & Present study \\
\hline \multicolumn{4}{|c|}{ a Sequences are listed in order of parental strain and then GenBank accession no. } \\
\hline \multicolumn{4}{|c|}{${ }^{\text {bParental }} \mathrm{RhCMV}_{68-1} \mathrm{BAC}$ used in the present study. } \\
\hline \multicolumn{4}{|c|}{${ }^{\mathrm{C}} \mathrm{RhCMV}_{68-1} / \mathrm{EBOV} / \mathrm{RL} 11 \mathrm{G}^{+} \mathrm{BAC}$ generated in the present study. } \\
\hline${ }^{\mathrm{d}}$ Full-length sequence & rated in the pre & t study; DQ120516. & as a large deletion. \\
\hline
\end{tabular}


The original nomenclature for $\mathrm{RhCMV}_{68-1}$ ORFs was established in 2003 and consisted of the prefix rh followed by a number (GenBank accession no. AY186194.1) 24. This nomenclature was modified and extended in 2012 by comparison with the sequence of $\mathrm{RhCMV}_{68-1}$ BAC (GenBank accession no. JQ795930.1) ${ }^{20}$. As this nomenclature related only to RhCMV and not other CMVs, a comparative analysis in 2006 of the sequence of RhCMV strain 180.92 (GenBank accession no. DQ120516.1) ${ }^{18}$ was used to develop a partially inclusive system in which RhCMV ORFs conserved in human CMV (HCMV) were given names corresponding to those in HCMV. A fully inclusive system applying across sequenced primate CMVs was developed in 2011 (GenBank accession no.

FJ483968.2 ${ }^{22}$, when the RhCMV genome annotation was improved further and orthologous ORFs in different CMVs were denoted by the same name. The principal names were those of HCMV ORFs, supplemented by those of ORFs specific to Old World monkey CMVs, which are prefixed by the letter $\mathrm{O}$. This nomenclature is used below and in the genetic map of the final product of the HHi-FiVe pipeline (Figure 1). In addition, when available, the alternative names are provided in Table 2, and the 2012 names are specified below in parentheses after first use of an inclusive name. Nucleotide descriptions are given in relation to the genome sequence regardless of ORF orientation. 
Table 2

Steps in repairing inactivated ORFs in $\mathrm{RhCMV}_{68-1} / \mathrm{EBOV}$ BAC.

\begin{tabular}{|c|c|c|c|c|c|c|c|}
\hline Step & ORF & 2003 ORFa & 2006 ORF $^{b}$ & 2012 ORF $^{c}$ & Mutation ${ }^{d}$ & Repaird & Locatione \\
\hline 1 & UL36 & rh61\&rh60 & rhUL36 & Rh61/Rh60 & Frameshifted in $\mathrm{T}_{8}$ & Replaced by $\mathrm{T}_{7}$ & $48669-48675$ \\
\hline \multirow[t]{4}{*}{2} & UL146C & NP & NP & NP & Wholly deleted & Replaced & 167033-171891 \\
\hline & UL146D & NP & NP & NP & Wholly deleted & Replaced & \\
\hline & UL146F & NP & NP & NP & Wholly deleted & Replaced & \\
\hline & UL146H & rh161 & NP & Rh161 & Partially deleted & Replaced & \\
\hline 3 & RL11D & rh08 & rh8 & Rh08 & Frameshifted in $\mathrm{C}_{11}$ & $\begin{array}{l}\text { Replaced by } \\
\mathrm{CAC}_{8}\end{array}$ & $6341-6350$ \\
\hline 4 & UL119 & rh152\&rh151 ${ }^{f}$ & rhUL119 & Rh152/Rh151 & $\begin{array}{l}\text { Terminated by stop } \\
\text { codon (TCA) }\end{array}$ & $\begin{array}{l}\text { Replaced by } \\
\text { CCA }\end{array}$ & $154761-154763$ \\
\hline 5 & US12E & rh197 & rh197 & Rh197 & $\begin{array}{l}\text { Terminated by stop } \\
\text { codon (CTA) }\end{array}$ & $\begin{array}{l}\text { Replaced by } \\
\text { CCA }\end{array}$ & 208625-208627 \\
\hline 6 & RL11E & NA & rh8.1 & Rh08.1 & $\begin{array}{l}\text { Frameshifted in } \\
\mathrm{CCAC}_{10}\end{array}$ & $\begin{array}{l}\text { Replaced by } \\
\mathrm{C}_{12}\end{array}$ & $6991-7002$ \\
\hline 7 & RL11B & rh06 & rh6 & Rh06 & Frameshifted in $\mathrm{C}_{11}$ & $\begin{array}{l}\text { Replaced by } \\
\text { TCCACCTCC }\end{array}$ & 5197-5208 \\
\hline \multirow[t]{2}{*}{8} & UL128 & NP & rhUL128 & NP & Wholly deleted & Replaced & \multirow[t]{2}{*}{$161705-167032$} \\
\hline & UL130 & NA & rhUL130 & Rh157.4 & Partially deleted & Replaced & \\
\hline \multirow[t]{2}{*}{9} & $\mathrm{RL} 11 \mathrm{G}$ & rh14 & rh13.1\&rh14 & Rh13.1 & $\begin{array}{l}\text { Frameshifted due to } \\
\text { insertion (CT) }\end{array}$ & Deleted & $\begin{array}{l}\text { Between } 12847 \\
\text { and } 12848\end{array}$ \\
\hline & & & & & Frameshifted in $A_{8}$ & Replaced by $A_{7}$ & $13059-13065$ \\
\hline
\end{tabular}

a Name of ORF in RhCMV $68-1$, GenBank accession no. AY186194.1 (Hansen et al., 2003) 24; NA, not annotated; NP, not present; \&, separate ORFs; some ORFs are partial because of lack of recognition of errors, mutations or splicing.

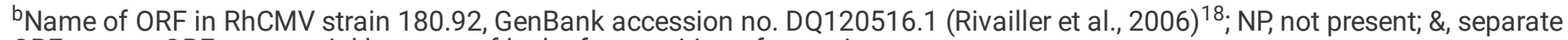
ORFs; some ORFs are partial because of lack of recognition of mutations.

'Name of ORF in RhCMV 68-1 BAC, GenBank accession no. JQ795930.1 (Malouli et al., 2012) ${ }^{20}$; NP, not present; /, spliced ORFs; some ORFs are partial because of lack of recognition of mutations.

dSequences correspond to the genome sequence regardless of ORF orientation.

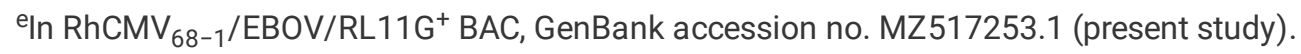

${ }^{\mathrm{f}}$ Apparently intended to be named rh151 but annotated rh141.

\section{Identification of mutated ORFs in $\mathrm{RhCMV}_{68-1} /$ EBOV BAC}

As noted previously, one of the complications with identifying mutations in $\mathrm{RhCMV}_{68-1}$ and $\mathrm{RhCMV}_{68-1} \mathrm{BAC}$ is that the original $\mathrm{RhCMV}_{68-1}$ sequence appears to contain numerous errors ${ }^{20}$. Thus, some of the differences between RhCMV $68-1$ and RhCMV $68-1$ BAC are due to these errors rather than to mutations generated during the construction of $\mathrm{RhCMV}_{68-1}$ BAC. We estimated the number of such errors at 20. They include substitutions and insertions or deletions (indels) in noncoding regions, substitutions in ORFs [RL1 (Rh01), RL11A (Rh05), RL11C (Rh07), RL11D (Rh08) and UL55 (Rh89); and RL11G (Rh13.1)], introducing an in-frame stop codon, although this may have been due to a subpopulation of mutants in $\mathrm{RhCMV}_{68-1}$ rather than an error), and frameshifts in ORFs [RL11D, COX2 (Rh10), UL34 (Rh57), UL71 (Rh100.1), US18 (Rh199) and US27D (Rh216)]. 
In order to ensure that the RhCMV component of the repaired $\mathrm{RhCMV}_{68-1} /$ EBOV BAC was as close in sequence as possible to the original $\mathrm{RhCMV}_{68-1}$ genome as perceived to have existed prior to isolation and serial passage in cell culture ${ }^{25}$, it was necessary to identify mutations in $\mathrm{RhCMV}_{68-1} \mathrm{BAC}$ (and hence in $\mathrm{RhCMV}_{68-1} / \mathrm{EBOV} \mathrm{BAC}$ ) that have resulted in inactivated ORFs. This involved detailed examination of an alignment of all available RhCMV genome sequences, which at the time did not include several reported since by Taher et al (2020) ${ }^{23}$; these recent sequences were incorporated at the end of the study and identified no additional mutations. This comparative exercise revealed a total of 13 putatively inactivated ORFs (Table 2). They fell into two categories: (i) those terminated by in-frame stop codons due to substitutions and those truncated or extended by frameshifts due to small indels (most located within or associated with homopolynucleotide tracts), and (ii) those partly or wholly missing due to large deletions or rearrangements. Seven ORFs [RL11B (Rh06), RL11D, RL11E (Rh08.1), RL11G, UL36 (Rh61/Rh60), UL119 (Rh152/Rh151) and US12E (Rh197)] distributed across the genome were in category (i) and required small-scale repair. Six ORFs [UL128, UL130 (Rh154.7), UL146C, UL146D, UL146F and UL146H] located within a region of the genome called UL/b', which contains ORFs involved in cellular tropism and immunomodulation ${ }^{19,26}$ were in category (ii) and required large-scale repair. These ORFs were supplemented by six other ORFs in UL/b' [UL131A (Rh157.6), UL132 (Rh160), UL148 (Rh159), UL147A, UL147 (Rh158) and UL146B (Rh158.1)] that, although intact and therefore probably not inactivated, were inverted as a block. These 19 ORFs were targeted for repair, replacement, or restoration in $\mathrm{RhCMV}_{68-1}$ /EBOV BAC.

Examination of the sequence alignment also indicated a few additional differences in six RhCMV $68-1$ BAC ORFs [03, UL41A (Rh67.1), UL45 (Rh72), UL74A, UL141 (Rh164) and US12B (Rh194)] that are not represented in RhCMV 68-1 or other RhCMV strains but caused predicted amino acid substitutions. Given the error-prone nature of the $\mathrm{RhCMV}_{68-1}$ sequence, the reality of these differences was not certain, and they were not targeted for repair.

\section{Pipeline for repairing mutated ORFs}

Targeted genetic manipulation of herpesvirus genomes is achieved by BAC-based recombineering followed by reconstitution of virus by transfection of BACs into permissive cells ${ }^{27}$. Off-site mutations are a concern when manipulating such large DNA constructs and reconstituting viruses. In the past, this problem has been addressed by creating viruses from revertant BACs in order to demonstrate that the intended manipulations are genetically and phenotypically reversible. However, this approach is regarded as inadequate because it does not control for off-site mutations that arise during reconstitution of virus; in our experience, this is often when such mutations occur. It is also not practical for vaccine development because of the labor-intensiveness and limited scope of phenotypic assays. To cope with this inherent vulnerability, we coupled BAC-based recombineering with responsive lllumina-based whole genome sequencing to create the HHi-FiVe pipeline for generating and validating BACs and reconstituted viruses (Figure 2).

We set out to use this pipeline to repair the mutations in $\mathrm{RhCMV}_{68-1} /$ EBOV BAC using BAC-based recombineering ${ }^{4,28,29}$. Recombinant BACs were screened initially by restriction fragment length polymorphism (RFLP) analysis to screen for appropriate changes to fragment mobility (Supplementary Figure 1). This was followed by whole genome sequencing of recombinant BACs at each stage. Overall, the complete process was accomplished in nine steps (Table 2).

\section{Small-scale repairs}

Six inactivated ORFs (RL11B, RL11D, RL11E, UL36, UL119 and US12E) required small-scale repair (Steps 1 and 3-7). Most mutations were addressed by restoring the perceived original sequence to reinstate the integrity of the ORF. However, an initial attempt at repairing RL11B at Step 7, which consisted of removing two $\mathrm{C}$ residues in a $\mathrm{C}_{11}$ homopolynucleotide tract to restore a $\mathrm{C}_{9}$ tract, resulted consistently in a $\mathrm{C}_{10}$ tract. Therefore, an alternative strategy was used that involved introducing synonomous substitutions within the tract. Repair of RL11G was also small-scale (see below).

\section{Large-scale repairs}

A total of $12 \mathrm{ORFs}$ in $\mathrm{UL} / \mathrm{b}^{\prime}$ had undergone extensive deletion or rearrangement during passage of $\mathrm{RhCMV}_{68-1}$, and the six ORFs that were completely or partially missing as a result were not amenable to small-scale repair. Instead, the whole region was replaced by a wild type version based on RhCMV strain 19936 (Table 1), using three synthetic DNA segments that together encompassed this region (Steps 2 and 8). The product of Step 8, which still contained two frameshift mutations in RL11G (see below), was denoted $\mathrm{RhCMV}_{68-1} / \mathrm{EBOV} / \mathrm{RL}_{11 \mathrm{G}^{-}} \mathrm{BAC}$.

Repair of RL11G

Page $7 / 24$ 
RL11G contained two separate mutations: a CT insertion in a (CT) $)_{2}$ tract, and further downstream, an A insertion in an $A_{7}$ tract. Each mutation resulted in a frameshift, the first removing the transmembrane domain of the encoded protein and the second restoring the correct reading frame near the end of the ORF. The first mutation was predicted to have been sufficient to inactivate RL11G on its own. RL11G is an orthologue of HCMV RL1320, which has been shown to mutate during viral growth in culture in all cell types tested ${ }^{30,31}$. Therefore, its repair was reserved for the final step (Step 9). This strategy was vindicated by the recent demonstration that a repaired version of RL11G in a BAC-derived version of $\mathrm{RhCMV}_{68-1}$ mutates in rhesus fibroblast cell culture ${ }^{23}$. Our approach was to delete RL11G completely and insert a full-length synthetic version in which the two frameshift mutations were repaired and two substitutions unique to $\mathrm{RhCMV}_{68-1}$ and $\mathrm{RhCMV}_{68-1}$-based BACs were replaced. The final product was denoted $\mathrm{RhCMV}_{68-1} / \mathrm{EBOV} / \mathrm{RL}_{11 \mathrm{G}^{+}} \mathrm{BAC}$ and was repaired in all the genes inactivated in $\mathrm{RhCMV}_{68-1} \mathrm{BAC}$ and $\mathrm{RhCMV}_{68-1} / \mathrm{EBOV} \mathrm{BAC}$ by premature termination, frameshifting, deletion, or rearrangement. As well as the intended manipulations and repairs, both $\mathrm{RhCMV}_{68-1} / \mathrm{EBOV}_{\mathrm{RL}} 11 \mathrm{G}^{-}$and $\mathrm{RhCMV}_{68-1} / \mathrm{EBOV} / \mathrm{RL}_{11 G}{ }^{+}$ $\mathrm{BAC}$ had one inconsequential difference from $\mathrm{RhCMV}_{68-1} / \mathrm{EBOV}$ : an additional $\mathrm{G}$ residue in a $\mathrm{G}_{7}$-tract in one copy of the terminal direct repeat of the viral genome.

\section{Stability of $\mathrm{RhCMV}_{68-1} / \mathrm{EBOV} / \mathrm{RL}_{11 \mathrm{G}^{-}}$and $\mathrm{RhCMV}_{68-1} / \mathrm{EBOV} / \mathrm{RL}_{11 G^{+}}$}

Viruses were reconstituted by transfecting $\mathrm{RhCMV}_{68-1} / \mathrm{EBOV} / \mathrm{RL}_{11 \mathrm{G}^{-}} \mathrm{BAC}$ or $\mathrm{RhCMV}_{68-1} / \mathrm{EBOV} / \mathrm{RL}_{11 \mathrm{G}^{+}} \mathrm{BAC}$ into rhesus fibroblast (Telo-RF) or human epithelial (hTERT RPE-1) cells and passaging further. When the cultures exhibited full cytopathic effect, DNA was extracted from infected cells or infected cell supernatant and sequenced. For each dataset, mutations were identified by visual inspection of an alignment of sequence reads to the anticipated viral genome sequence, and their abundance was calculated by counting the proportion of reads containing the mutation. This approach allowed mutations representing major subpopulations to be identified and quantified, and permitted the prevalence of these mutations to be examined in other samples in the same passage series even if present in minor subpopulations. However, minor subpopulations that did not reach sufficient representation in any sample in the series might not have been detected. Three clones (clones 1-3) of $\mathrm{RhCMV}_{68-1} / \mathrm{EBOV} / \mathrm{RL}_{11 \mathrm{G}^{-}} \mathrm{BAC}$ and one clone (clone 1) of $\mathrm{RhCMV}_{68-1} / \mathrm{EBOV} / \mathrm{RL}_{11 \mathrm{G}^{+}} \mathrm{BAC}$ were transfected, the latter having been derived from one of the former $\mathrm{RhCMV}_{68-1} / \mathrm{EBOV} / \mathrm{RL}_{11 \mathrm{G}^{-}}$ $\mathrm{BAC}$ clones (clone 2). The sequences of the $\mathrm{RhCMV}_{68-1} / \mathrm{EBOV} / \mathrm{RL}_{11 \mathrm{G}^{-}} \mathrm{BAC}$ clones were identical to each other. The scheme for reconstituting and passaging viruses is summarised in Figure 3 and the 16 samples sequenced (Samples $A-P$ ) are indicated by red font.

Reconstitution of $\mathrm{RhCMV}_{68-1} / \mathrm{EBOV} / \mathrm{RL}_{11 G^{-}} \mathrm{BAC}$ clone 1 in Telo-RF cells generated a 1 bp frameshifting deletion in UL128 and a 193 bp frameshifting deletion in UL116 (Rh148). At passages 1, 4 and 8 in Telo-RF cells (Samples A-C), the proportions of the UL128 mutation were 85,99 and $100 \%$, respectively, and the proportions of the UL 116 mutation were 4,0 and $0 \%$, respectively. Virus at passage 1 in Telo-RF cells was also transferred to hTERT RPE-1 cells. At passages 2 and 5 in these cells (Samples D-E), the proportions of the UL128 mutation were 40 and $30 \%$, respectively, and the proportions of the UL 116 mutation were 38 and $66 \%$, respectively. Thus, both mutations were present in passage 1 in Telo-RF cells, and the UL128 mutation was selected for in Telo-RF cells but selected against in hTERT RPE-1 cells. In contrast, whereas the UL116 mutation was selected against in Telo-RF cells, it was selected for in hTERT RPE-1 cells. Reconstitution of RhCMV 68-1 $_{1} /$ EBOV/RL11G- BAC clone 2 in Telo-RF cells generated a 1022 bp deletion truncating UL128 and UL130 and nine linked C to T substitutions in US12 (Rh190). Among the substitutions, four were synonymous, three were nonsynonymous, and two introduced in-frame stop codons. At passage 1 in Telo-RF cells (Sample F), the percentages of the UL128 and US12 mutations were both $77 \%$, implying that they were present in the same genome. In contrast, reconstitution of $\mathrm{RhCMV}_{68-1} / \mathrm{EBOV} / \mathrm{RL}_{11 \mathrm{G}^{-}}$BAC clone 3 in Telo-RF cells generated no major mutations (Sample G). Selection of mutations in one or more of the three adjacent genes UL128, UL130 and UL131A is a recognised feature of RhCMV and HCMV when passaged in fibroblast cells ${ }^{18,30-32}$. Additional mutations may be carried fortuitously with these mutations when present in the same genome, or they may be selected independently. In contrast, UL128, UL130 and UL131A are essential for growth of HCMV and RhCMV in non-fibroblast cells because they encode a glycoprotein complex that is required for viral entry into these cells ${ }^{32,33}$. Consistent with this, no major mutations were generated by reconstitution of $\mathrm{RhCMV}_{68-1} /$ EBOV/RL11G ${ }^{-}$BAC clone 1 in hTERT RPE-1 cells at passages 1,5 and 10 (Samples $\mathrm{H}-\mathrm{J}$ ), in a mixture of stocks from passages 3-9 in this series (Sample K) grown in hTERT RPE-1 cells, in an independent stock grown from passage 3 in this series grown in hTERT RPE-1 cells, in a mixture of hTERT RPE- 1 and Telo-RF cells or in Telo-RF cells alone (Samples $L-N$ ), or in an independent stock grown from passage 1 in this series in HTERT RPE-1 cells (Sample 0). 
In contrast to the results obtained with the $\mathrm{RhCMV}_{68-1} / \mathrm{EBOV} / \mathrm{RL}_{11 \mathrm{G}^{-}}$clones, reconstitution of $\mathrm{RhCMV}_{68-1} / \mathrm{EBOV} / \mathrm{RL}_{11 \mathrm{G}^{+}} \mathrm{BAC}$ clone 1 in RPE-1 cells generated a major mutation at passage 1 in these cells consisting of a 12,778 bp sequence extending from within RL1 to close downstream from RL11H that had been replaced by a 1,786 bp bacterial sequence (Sample P). The proportion of genomes in which RL11G had not been inactivated by this indel was close to $0 \%$. We conclude that virus reconstituted from the

$\mathrm{RhCMV}_{68-1} / \mathrm{EBOV} / \mathrm{RL}_{11 \mathrm{G}^{-}}$BACs was genetically unstable when passaged in Telo-RF cells, accumulating mutations not only in UL128, UL130 and UL131A but also in other parts of the genome. In contrast, the genome was stable when virus was passaged in hTERT RPE1 cells. Virus reconstituted from $\mathrm{RhCMV}_{68-1} / \mathrm{EBOV}^{\mathrm{RL}} 11 \mathrm{G}^{+} \mathrm{BAC}$ was unstable in hTERT RPE-1 cells, in which RL11G was inactivated.

\section{Cellular tropism of RhCMV/EBOV/RL11G-}

The purpose of repairing $\mathrm{RhCMV}_{68-1} / \mathrm{EBOV} \mathrm{BAC}$ is eventually to examine its potential as a model transmissible vaccine platform for providing protective immunity against EBOV following animal-to-animal dissemination of the vaccine. The extent to which RL11G is required for dissemination remains to be determined, but the use of virus reconstituted from $\mathrm{RhCMV}_{68-1} / \mathrm{EBOV} / \mathrm{RL}_{11 \mathrm{G}^{+}} \mathrm{BAC}$ was precluded because of the instability of RL11G in various cell types tested following reconstitution and passage (Figure 3; data not shown), which is consistent with previous findings for $\mathrm{RhCMV}^{23}$, and the RL11G orthologue (RL13) in HCMV 30,31 . In contrast, the genome integrity of $\mathrm{RhCMV}_{68-1} / \mathrm{EBOV} / \mathrm{RL}_{11 \mathrm{G}^{-}} \mathrm{BAC}$ was maintained over multiple passages in hTERT RPE-1 cells. To assess cellular tropism, $\mathrm{RhCMV}_{68-1} /$ EBOV was reconstituted from $\mathrm{RhCMV}_{68-1} / \mathrm{EBOV}_{\mathrm{BAC}}$ in Telo-RF cells, and $\mathrm{RhCMV}_{68-1} / \mathrm{EBOV} \mathrm{RL}_{11 \mathrm{G}^{-}}$was reconstituted in hTERT RPE-1 cells. Viral growth was measured in infected Telo-RF cells and hTERT RPE-1 cells. Only $\mathrm{RhCMV}_{68-1} / \mathrm{EBOV} / \mathrm{RL}_{11 \mathrm{G}^{-}}$was able to replicate in both cell lines (Figure 4).

\section{EBOV-GP expression by $\mathrm{RhCMV}_{68-1} / \mathrm{EBOV} \mathrm{RL} 11 \mathrm{G}^{-}$}

To examine transcription of EBOV-GP, hTERT RPE-1 cells were infected with $\mathrm{RhCMV}_{68-1} / \mathrm{EBOV} / \mathrm{RL}_{11 \mathrm{G}^{-}}$, total infected cell RNA was harvested at $21 \mathrm{~d}$ p.i., stranded RNAseq data were generated from the polyadenylated RNA fraction, and the relative proportions of sense and antisense RNAs produced from individual coding regions were calculated (Supplementary Table 1). Sense transcripts predominated ( $93.61 \%$ of all sense and antisense transcripts combined), and EBOV-GP was the sixth most highly expressed ( $2.31 \%)$ sense RNA of the 185 coding regions assessed. Transcripts from the RL11 family were notable by their generally low level of expression.

Finally, to examine translation of EBOV-GP, Telo-RF cells were infected with $\mathrm{RhCMV}_{68-1}$ or $\mathrm{RhCMV}_{68-1} / \mathrm{EBOV} / \mathrm{RL}_{11 G^{-}}$, and hTERT RPE1 cells were infected with $\mathrm{RhCMV}_{68-1} / \mathrm{EBOV} / \mathrm{RL}_{11 \mathrm{G}^{-}}$. Immunoblotting was carried out on infected cell proteins using an EBOV-GPspecific monoclonal antibody (mAb) to detect EBOV-GP, a RhCMV UL44 protein-specific antibody to confirm viral infection, and an antiglyceraldehyde-3-phosphate dehydrogenase (GAPDH) mAb to monitor cellular protein expression. EBOV-GP was expressed in increasing amounts by $\mathrm{RhCMV}_{68-1} / \mathrm{EBOV} \mathrm{RL}_{11 \mathrm{G}^{-}}$in Telo-RF cells at least until $7 \mathrm{~d}$ p.i. (Figure 5A) and in hTERT RPE-1 cells at least until 15 d p.i. (Figure 5B).

\section{Discussion}

This work is a proof-of-concept study aimed at establishing the HHi-FiVe pipeline for efficient, high-fidelity genetic manipulation of herpesvirus-based vectors as a means for providing a rapid turnaround platform for developing vaccines. Over the past decade, various recombineering methodologies have been invented that enable precise engineering of large DNA constructs on both the small and large scales. However, even following confirmation of the accuracy of the intended manipulations, off-target mutations remain a concern, especially when, as in this case, multiple iterative changes are made within a single BAC lineage. Added to this is the serious potential for mutation during reconstitution of virus from a BAC. To allay these concerns, we screened BACs initially by RFLP analysis and then assessed their full integrity by complete genome sequencing. We also sequenced various viruses reconstituted from the BACs generated in the final two steps $\left(\mathrm{RhCMV}_{68-1} / \mathrm{EBOV} / \mathrm{RL}_{11 \mathrm{G}^{-}} \mathrm{BAC}\right.$ and $\left.\mathrm{RhCMV}_{68-1} / \mathrm{EBOV} / \mathrm{RL} 11 \mathrm{G}^{+} \mathrm{BAC}\right)$. Since the case was complex and the pipeline was untested, RFLP screening and genome sequencing were used extensively, often with multiple clones at each step. In total, 974 BACs were subjected to RFLP analysis and 83 BACs and 16 reconstituted viruses were examined by whole genome sequencing. Although most of the repairs were achieved as intended, some were problematic (e.g., the initial attempt at repairing RL11B at Step 7) or because off-site substitutions were introduced. In addition, sequencing the reconstituted viruses provided critical 
information on genetic stability, leading to the conclusion that virus reconstituted from $\mathrm{RhCMV}_{68-1} / \mathrm{EBOV} / \mathrm{RL}_{11 \mathrm{G}^{-}}$, unlike that reconstituted from $\mathrm{RhCMV}_{68-1} / \mathrm{EBOV} / \mathrm{RL}_{11 \mathrm{G}^{+}} \mathrm{BAC}$, was stable in epithelial (hTERT RPE-1) cells.

We chose to establish the $\mathrm{HHi}$-FiVe pipeline by repairing $\mathrm{RhCMV}_{68-1} / \mathrm{EBOV}$ because of the potential of the reconstituted virus to protect rhesus macaques challenged with lethal EBOV infection by transmitted, rather than parenteral subcutaneously administered vaccination. This decision also had the advantage of involving a case in which small- and large-scale repairs were accomplished in several steps, each consisting of multiple manipulations. The success of the pipeline in this situation indicates that it is likely to be broadly applicable. The complexity of this case is inherent in the development of research on $\mathrm{RhCMV}_{68-1}$, which, because the virus is highly mutated, lacks key phenotypic properties, including the ability to infect non-fibroblast cells, and in the fact that all available BACs are derived from this strain. This has led to previous attempts to restore wild type properties by repairing $\mathrm{RhCMV}_{68-1} \mathrm{BAC}_{\mathrm{T}} \mathrm{The}$ resulting BACs include one in which UL36 and the region containing UL128, UL130 and UL131A were repaired ${ }^{32}$, and one containing a full-length genome that has been repaired more extensively ${ }^{23}$ but retains the frameshifts in RL11B, RL11D and RL11E. These repaired BACs have formed an important prelude to experimentation on the immunobiology and pathology of RhCMV in its natural host. Our repair of $\mathrm{RhCMV}_{68-1} / \mathrm{EBOV}$ was, by contrast, vaccine-oriented and corrected all inactivated (i.e., prematurely terminated, frameshifted, deleted, or rearranged) ORFs.

In each of the instances described above, repairs were made by identifying mutated and nonmutated sequences from genome alignments of $\mathrm{RhCMV}_{68-1}$ and other RhCMV strains. Since all the strains had been isolated in cell culture and were themselves potentially mutated, this involved a degree of interpretation, making it difficult to be sure that all mutations had been identified. A more straightforward approach would be to construct a BAC from a strain that has been sequenced directly from the host and passaged minimally, and then to repair the BAC accordingly, as has been done with HCMV ${ }^{31}$. However, this approach carries the inherent risk that any new BAC may represent a virus with phenotypic differences from those of $\mathrm{RhCMV}_{68-1}$, the immunology of which has been characterized extensively during its development as a vaccine platform (further details are below). The RhCMV case also raises the further complexity that the virus reconstituted from a repaired $B A C\left(\mathrm{RhCMV}_{68-1} / \mathrm{EBOV} / \mathrm{RL}_{11} \mathrm{G}^{+}\right)$is unstable, with mutants in $\mathrm{RL} 11 \mathrm{G}$ quickly being selected in cell culture. Alternative solutions are to use a stable virus in which the problematic gene remains inactivated $\left(\mathrm{RhCMV}_{68-1} / \mathrm{EBOV} / \mathrm{RL}_{11 \mathrm{G}}{ }^{-}\right)$or is placed under conditional control, as has been done for both $\mathrm{RhCMV}^{23}$ and HCMV 31,34 . The former solution is technically the simpler, but requires the phenotype of interest not to depend on the inactivated gene. It may be practical if the mutation is simple and can revert easily under selective pressure.

Herpesvirus-based vectors are showing considerable promise for use as conventional vaccines to control multiple pathogens that heretofore have been difficult to control ${ }^{3,8}$. In this context, herpesvirus-based vectors, in particular those based on CMVs, have been shown to have a distinct immunological profile associated with unique T-cell based antigen recognition based on MHC- $\mathrm{E}^{35}$. CMV-based vaccines have also been shown to provide immunological protection when administered via direct parenteral inoculation against lethal EBOV challenge in rhesus macaques, thus providing the basis for the present study ${ }^{5}$. However, most highly pathogenic emerging viruses spill over into human populations from inaccessible wild animal populations ${ }^{36}$, which poses a considerable limitation on the use of directly administered vaccines. The features of CMVs thus motivate the development of CMV-based vectors as a transmissible vaccine platform to achieve high immune coverage in such situations ${ }^{6,13,14}$. Our study has provided the means and experience whereby the efficient production of precision-made, genetically validated herpesvirus-based vectors can contribute to the further development of this platform. Towards this goal, the virus reconstituted from $\mathrm{RhCMV}_{68-1} / \mathrm{EBOV} / \mathrm{RL}_{11 \mathrm{G}^{-}} \mathrm{BAC}$ using the HHi-FiVe pipeline is currently being tested for its ability to act as a transmissible vaccine against lethal EBOV challenge in the rhesus macaque model.

\section{Methods}

\section{Cell lines}

Human telomerase-immortalized human retinal pigmented epithelial (hTERT RPE-1) cells (ATCC CRL-4000) and human telomeraseimmortalized rhesus fibroblast cells (Telo-RF) cells ${ }^{37}$ were maintained in complete Dulbecco's modified Eagle's medium (DMEM) supplemented with $10 \%\left(\mathrm{v} / \mathrm{v}\right.$ ) fetal calf serum (FCS), $100 \mathrm{IU} / \mathrm{ml}$ penicillin and $100 \mu \mathrm{g} / \mathrm{ml}$ streptomycin at $37^{\circ} \mathrm{C}$ in an atmosphere of 5 $\%(\mathrm{v} / \mathrm{v}) \mathrm{CO}_{2}$. 


\section{$\mathrm{RhCMV}_{68-1}$-based BACs}

The parental BACs used were the original $\mathrm{RhCMV}_{68-1} \mathrm{BAC}^{17}$ and derivative $\left(\mathrm{RhCMV}_{68-1} / \mathrm{EBOV}^{\mathrm{BAC}}{ }^{5,17}\right)$ bearing EBOV-GP in place of RhCMV UL83B (Rh112). The circular sequence of $\mathrm{RhCMV}_{68-1} /$ EBOV BAC consists of the unique region (U) of the viral genome and three tandem copies of a direct repeat that forms the terminal direct repeat (TR) of the viral genome (one copy at each end), with the BAC vector inserted into a location in U between genes US1 (Rh181) and US2 (Rh182). The transgene consists of a synthetic codonoptimised version of the Zaire ebolavirus/H.sapiens-tc/COD/1976/Yambuku-Mayinga EBOV-GP ORF encoding the EBOV glycoprotein (GenBank accession no. AF086833.2) with its 3' end extended to encode a 14 amino acid residue V5 epitope tag, followed by downstream noncoding sequences. Two unintended but inconsequential differences were noted in the $\mathrm{RhCMV}_{68-1} / \mathrm{EBOV}$ clone used for repair5: a non-synonymous substitution in EBOV-GP that results in an A to T amino acid substitution at codon 474 (a T residue is encoded at this position in some EBOV strains), and a noncoding substitution in the viral sequence very close to the right end of the transgene.

\section{$\mathrm{RhCMV}_{68-1} /$ EBOV-based BAC recombineering}

Mutations in $\mathrm{RhCMV}_{68-1} /$ EBOV-based BACs in Escherichia coli GS1783 were repaired by using lambda Red recombination and en passant mutagenesis as described previously ${ }^{38}$. For small-scale repairs, a PCR product containing the repaired sequence and a selectable marker with an adjacent I-Scel restriction site was recombined into the BAC. The selectable marker was removed by the $E$. coli GS1783-encoded I-Scel endonuclease, leaving a scarless repair. RL11G was repaired by replacing the mutated ORF with a selectable marker for kanamycin resistance and then replacing this marker by a synthetic, repaired version of RL11G by using a selectable marker for spectinomycin resistance. For large-scale repairs, a 7.3 kbp region (UL/b') [UL124 (Rh156.2) to UL145 (Rh162)] was removed using a Kan marker and then repaired in three stages by en passant mutagenesis using three synthetic sequences comprising a wild type version of this region based on strain 19936 (KX689268.1).

\section{RFLP analysis}

Correct lambda Red recombination and en passant mutagenesis were confirmed using RFLP. Mutated and repaired RhCMV $68-1 / \mathrm{EBOV}$ based BACs in E. coli GS1783 were grown overnight in Luria-Bertani (LB) broth (Thermo Fisher Scientific) containing $17.5 \mu \mathrm{g} / \mathrm{ml}$ chloramphenicol. BAC DNA was extracted, digested with various restriction endonucleases, and subjected to agarose gel electrophoresis. The gels were stained with $0.5 \mu \mathrm{g} / \mathrm{ml}$ ethidium bromide and photographed under ultraviolet illumination to identify differences in DNA fragment mobility.

\section{$\mathrm{RhCMV}_{68-1}$-based $\mathrm{BAC}$ virus reconstitution}

BAC DNA $(4 \mu \mathrm{g})$ was transfected into resuspended cells $\left(1 \times 10^{6}\right.$ hTERT RPE-1 or Telo-RF cells for each well of a 6-well plate) using Genjet (SignaGen Laboratories) according to the manufacturer's instructions. The monolayers were expanded when confluency was reached and all cells showed cytopathic effect. At this time, the cell supernatant was collected, centrifuged at $5000 \times \mathrm{g}$ for $10 \mathrm{~min}$, aliquoted and store at $-80^{\circ} \mathrm{C}$. DNA was extracted for complete genome analysis from an aliquot of the infected cell supernatant or a fraction of the cell lysate using an innuPREP DNA Mini kit (Analytik Jena) according to the manufacturer's instructions.

\section{Genome sequencing}

Genome sequences were determined by standard techniques. Briefly, DNA (100 ng) from a BAC or a virus in infected cells or infected cell supernatant was sheared in a Covaris $S 220$ sonicator to approximately $450 \mathrm{bp}$, and a sequencing library was prepared by carrying out seven cycles of PCR with indexed primers (New England Biolabs) using a Kapa LTP library preparation kit (Kapa Biosystems). Libraries were sequenced using MiSeq or NextSeq instruments (Illumina), generating datasets of 611,268-22,429,774 (BAC samples) or 2,767,034-9,488,118 (virus samples) paired-end 150 or 300 nucleotide (nt) reads per sample.

Low-quality reads and sequencing adapters were removed from the datasets using Trim Galore v. 0.4.0 (https://github.com/FelixKrueger/TrimGalore), and the remaining reads were aligned with an appropriate reference genome using Bowtie 2 v. 2.3.1 ${ }^{39}$. Alignments were visualized using Tablet v. 1.19.09.03 ${ }^{40}$. If necessary, the reference genome was corrected iteratively and fresh alignments were made. The average coverage depth of the final sequences was 136-11,175 (BAC samples) or 19-2,364 (virus samples) reads/nt. Of the BACs and viruses analysed, all but one were derived from $\mathrm{RhCMV}_{68-1}$. The exception was sequenced to supplement Table 1, and consisted of a minor population of full-length genomes present in a stock of RhCMV strain 
180.92 , which consisted mainly of genomes bearing a large deletion in $U L / b^{\prime 41}$. In this case, DNA was isolated from virus generated by transfecting a historical stock of purified virion DNA into Telo-RF cells.

\section{Cellular tropism analysis}

Multistep growth curves were conducted in triplicate in hTERT RPE-1 cells and Telo-RF cells in 6 -well plates ( $5 \times 10^{4}$ cells/well) and infected at the indicated multiplicity of infection (MOI) based on plaque-forming units (PFU)/cell. At $4 \mathrm{~h}$ post infection (p.i.), the cells were washed twice with Dulbecco's phosphate-buffered saline (DPBS), and fresh medium was added. Total supernatant was then collected at various times p.i., followed by washing the monolayers once with DPBS and adding fresh medium. Viral titer in the supernatant was determined by standard plaque assay on Telo-RF cells. Growth curves were performed at least twice.

\section{Viral transcription analysis}

Confluent hTERT RPE-1 cells in two $175 \mathrm{~cm}^{2}$ flasks were infected with $\mathrm{RhCMV}_{68-1} / \mathrm{EBOV} / \mathrm{RL}_{11 \mathrm{G}}{ }^{-}$at a MOI of $0.05 \mathrm{PFU} / \mathrm{cell}$. The medium was replaced with fresh medium at $14 \mathrm{~d}$ p.i. At $21 \mathrm{~d}$ p.i., the medium was removed, and the infected cells were washed with DPBS and trypsinized using $0.05 \%(\mathrm{w} / \mathrm{v})$ trypsin in $0.02 \%(\mathrm{w} / \mathrm{v})$ ethylenediaminetetraacetic acid (EDTA) in Hank's balanced salt solution (HBSS). The detached cells from each flask were transferred to a RNAse-free $15 \mathrm{ml}$ conical tube and pelleted by centrifugation at $300 \mathrm{xg}$ for $5 \mathrm{~min}$. The supernatant was removed, and the pellets were stored at $-80^{\circ} \mathrm{C}$. RNA was isolated from the pellets using a RNeasy mini kit (QIAGEN), employing additional steps for virus inactivation. These included incubating at $20^{\circ} \mathrm{C}$ for 10 min after disrupting the cells by adding buffer RLT (QIAGEN) and incubating at $20^{\circ} \mathrm{C}$ for $20 \mathrm{~min}$ after adding $70 \%(\mathrm{v} / \mathrm{v})$ ethanol to the homogenised lysate. RNA was stored at $-80^{\circ} \mathrm{C}$.

Three separate DNA sequencing libraries were prepared from polyadenylated RNA selected from each sample using a TruSeq stranded mRNA library prep kit (Illumina) with IDT for Illumina TruSeq RNA UD indexes (Illumina). An aliquot of 500 ng of RNA was used for each library, and the TruSeq stranded mRNA protocol was followed with the exception that 12 PCR cycles were performed. The six indexed libraries were pooled and sequenced on a NextSeq 500/550 mid output kit v2.5 (300 cycles) (Illumina), generating approximately 40 million paired-end $150 \mathrm{nt}$ reads per dataset.

Each dataset was quality-filtered using Trim Galore, sorted into sense and antisense reads using Samtools v. 1.13 (http://www.htslib.org) and mapped to the individual $\mathrm{RhCMV}_{68-1} / \mathrm{EBOV} / \mathrm{RL}_{11 \mathrm{G}^{-}}$ORFs using Bowtie 2 with the 'local' option. These ORFs included that of mutated RL11G and were supplemented by the sequence encoding one long noncoding RNA (RNA4.9). The number of reads mapping to each coding region was determined by visualising the alignment using Tablet and expressed as the number of reads per kbp per million sense or antisense reads mapping to all coding regions. The relative proportion of each RNA relative to the total was then calculated as a percentage for each dataset and expressed as an average.

\section{EBOV-GP protein expression analysis}

Telo-RF cell monolayers in 6-well plates $\left(5 \times 10^{4}\right.$ cells/well) were infected with $\mathrm{RhCMV}_{68-1}$ (reconstituted from $\mathrm{RhCMV}_{68-1} \mathrm{BAC}$ ) or $\mathrm{RhCMV}_{68-1} / \mathrm{EBOV} / \mathrm{RL}_{11 \mathrm{G}^{-}}$at an MOI of $0.2 \mathrm{PFU} /$ cell, and hTERT RPE-1 cells were infected with $\mathrm{RhCMV}_{68-1} / \mathrm{EBOV} / \mathrm{RL} 11 \mathrm{G}^{-}$at an MOI of $0.4 \mathrm{PFU} /$ cell. At various times p.i., the medium was removed, and the monolayers were lysed in boiling $2 \times$ SDS-PAGE sample buffer (125 mM Tris-HCl pH 6.8, 4 \% (w/v) SDS, $20 \%$ (v/v) glycerol and 10\% (v/v) 2-mercaptoethanol). Equal volumes of cell lysates were subjected to SDS-PAGE followed by semi-dry transfer to nitrocellulose membranes (GE Healthcare). Primary antibodies were applied at the dilutions indicated: anti-EBOV-GP protein (mAb clone 12/1.1; courtesy of Dr Ayato Takada; 1:10,000), anti-RhCMV UL44 protein (courtesy of Dr Thomas Shenk; 1:2) and anti-GAPDH (mAb clone 14C10, Cell Signalling; 1:1000). Compared to antibodies directed against the $\mathrm{V} 5$ epitope tag incorporated into EBOV GP expressed by the $\mathrm{RhCMV}_{68-1} / \mathrm{EBOV}$ vectors, the anti-EBOV-GP mAb gave consistently higher signal and was used for expression analysis. Secondary antibodies (horseradish peroxidase (HRP)-labeled; Dako) were applied at the dilutions indicated: anti-mouse $\operatorname{HRP}(1: 5,000)$ and anti-rabbit $\operatorname{HRP}(1: 5,000)$. The membranes were incubated overnight with primary antibody at $4^{\circ} \mathrm{C}$, and then for $1 \mathrm{~h}$ at room temperature with the secondary antibody in TBS-T (0.1\% (v/v) Tween20, $50 \mathrm{mM}$ Tris and $150 \mathrm{mM} \mathrm{NaCl}, \mathrm{pH}$ 7.5) containing $5 \%(\mathrm{w} / \mathrm{v})$ skimmed milk, and then washed three times for 5 min with TBS-T. The target proteins on the membranes were visualised by enhanced chemiluminescence (GE Healthcare) and imaged using a Fusion Capture Advance FX7 16.15 (Peqlab) instrument.

\section{Declarations}

Page $12 / 24$ 
We thank Dr Thomas Shenk (Princeton University, NJ, USA) for providing the antibody against the RhCMV UL44 protein, Dr Ayato Takada (Hokkaido University, Sapporo, Japan) for providing the mAb against EBOV-GP, Dr Salvatore Camiolo (MRC-University of Glasgow Centre for Virus Research, Glasgow, UK) for advice on analysing transcriptomic data, and Drs Gregory Smith (Northwestern University, IL, USA) and Nikolaus Osterrieder (Institut für Virologie, Berlin, Germany) for providing the en passant system. This study was funded by the U.S. Defense Advanced Research Projects Agency (DARPA), under agreement number D18AC00028. The funder had no role in content of the publication or in decision to publish.

\section{AUTHOR CONTRIBUTIONS}

M.A.J, A.J.D., W.B. and P.A.B. conceived and designed the study with assistance from members of the UCD PREEMPT Consortium. M.A.J., A.J.D., W.B., and P.A.B., drafted the manuscript with assistance from E.O., T.M., J.N., V.M. and K.A.S. The experiments were performed by T.M., E.O., J.N., Y.W., S.H., A.K., H.N., and R.A. A.J.D. carried out sequence analysis with assistance from J.N., M.V., and J.H. All authors reviewed the manuscript.

\section{DATA AVAILABILITY}

The data supporting the findings of this study are available from public databases as stated or from the corresponding author upon reasonable request.

\section{COMPETING INTERESTS}

M.A.J., T.M., Y.W., S.H., and H.N are employed, at least in part, by TVG. The remaining authors declare no competing interests.

\section{References}

1. Ampe, B., et al. Assessment of the long-term effect of vaccination on transmission of infectious bovine rhinotracheitis virus in cattle herds hyperimmunized with glycoprotein E-deleted marker vaccine. Am J Vet Res 73, 1787-1793 (2012).

2. Parker, D., de Wit, S., Houghton, H. \& Prandini, F. Assessment of impact of a novel infectious bursal disease (IBD) vaccination programme in breeders on IBD humoral antibody levels through the laying period. Vet Rec Open 1, e000016 (2014).

3. Hansen, S.G., et al. Profound early control of highly pathogenic SIV by an effector memory T-cell vaccine. Nature 473, 523-527 (2011).

4. Hansen, S.G., et al. Effector memory T cell responses are associated with protection of rhesus monkeys from mucosal simian immunodeficiency virus challenge. Nat Med 15, 293-299 (2009).

5. Marzi, A., et al. Cytomegalovirus-based vaccine expressing Ebola virus glycoprotein protects nonhuman primates from Ebola virus infection. Sci Rep 6, 21674 (2016).

6. Tsuda, Y., et al. A replicating cytomegalovirus-based vaccine encoding a single Ebola virus nucleoprotein CTL epitope confers protection against Ebola virus. PLoS NegI Trop Dis 5, e1275 (2011).

7. Tsuda, Y., et al. A cytomegalovirus-based vaccine provides long-lasting protection against lethal Ebola virus challenge after a single dose. Vaccine 33, 2261-2266 (2015).

8. Hansen, S.G., et al. Prevention of tuberculosis in rhesus macaques by a cytomegalovirus-based vaccine. Nat Med 24, 130-143 (2018).

9. Beverley, P.C., et al. A novel murine cytomegalovirus vaccine vector protects against Mycobacterium tuberculosis. J Immuno/ 193, 2306-2316 (2014).

10. Hansen, S.G., et al. Cytomegalovirus vectors expressing Plasmodium knowlesi antigens induce immune responses that delay parasitemia upon sporozoite challenge. PLoS One 14, e0210252 (2019).

11. Jarvis, M.A., Hansen, S.G., Nelson, J.A. \& Fruh, K. Cytomegaloviruses: From Molecular Pathogenesis to Intervention. Vol. 2 (ed. Reddehase, M.J.) (Caister Academic Press, Norwich, UK., 2013).

12. Hansen, S.G., et al. Evasion of CD8+ T cells is critical for superinfection by cytomegalovirus. Science 328, 102-106 (2010).

13. Murphy, A.A., Redwood, A.J. \& Jarvis, M.A. Self-disseminating vaccines for emerging infectious diseases. Expert Rev Vaccines 15, 31-39 (2016). 
14. Nuismer, S.L., et al. Bayesian estimation of Lassa virus epidemiological parameters: Implications for spillover prevention using wildlife vaccination. PLoS Negl Trop Dis 14, e0007920 (2020).

15. Ruzsics, Z., Borst, E.M., Brune, W. \& Messerle, M. Cytomegaloviruses: From Molecular Pathogenesis to Intervention. Vol. 1 (ed. Reddehase, M.J.) 38-58 (Caister Academic Press, Norwich, UK., 2013).

16. Asher, D.M., Gibbs, C.J., Jr., Lang, D.J., Gajdusek, D.C. \& Chanock, R.M. Persistent shedding of cytomegalovirus in the urine of healthy Rhesus monkeys. Proc Soc Exp Biol Med 145, 794-801 (1974).

17. Chang, W.L. \& Barry, P.A. Cloning of the full-length rhesus cytomegalovirus genome as an infectious and self-excisable bacterial artificial chromosome for analysis of viral pathogenesis. J Virol 77, 5073-5083 (2003).

18. Rivailler, P., Kaur, A., Johnson, R.P. \& Wang, F. Genomic sequence of rhesus cytomegalovirus 180.92: insights into the coding potential of rhesus cytomegalovirus. J Virol 80, 4179-4182 (2006).

19. Oxford, K.L., et al. Protein coding content of the ULb' region of wild-type rhesus cytomegalovirus. Virology 373, 181-188 (2008).

20. Malouli, D., et al. Reevaluation of the coding potential and proteomic analysis of the BAC-derived rhesus cytomegalovirus strain 68-1. J Virol 86, 8959-8973 (2012).

21. Burwitz, B.J., et al. Cross-Species Rhesus Cytomegalovirus Infection of Cynomolgus Macaques. PLoS Pathog 12, e1006014 (2016).

22. Davison, A.J., et al. Cytomegaloviruses: From Molecular Pathogenesis to Intervention. Vol. 1 (ed. Reddehase, M.J.) (Caister Academic Press, Norwich, UK., 2013).

23. Taher, $\mathrm{H}$., et al. In vitro and in vivo characterization of a recombinant rhesus cytomegalovirus containing a complete genome. PLoS Pathog 16, e1008666 (2020).

24. Hansen, S.G., Strelow, L.I., Franchi, D.C., Anders, D.G. \& Wong, S.W. Complete sequence and genomic analysis of rhesus cytomegalovirus. J Virol 77, 6620-6636 (2003).

25. Gill, R.B., et al. Coding potential of UL/b' from the initial source of rhesus cytomegalovirus Strain 68-1. Virology 447, 208-212 (2013).

26. Oxford, K.L., et al. Open reading frames carried on UL/b' are implicated in shedding and horizontal transmission of rhesus cytomegalovirus in rhesus monkeys. J Viro/ 85, 5105-5114 (2011).

27. Wagner, M., Ruzsics, Z. \& Koszinowski, U.H. Herpesvirus genetics has come of age. Trends Microbiol 10, 318-324 (2002).

28. Tischer, B.K., Smith, G.A. \& Osterrieder, N. En passant mutagenesis: a two step markerless red recombination system. Methods Mol Biol 634, 421-430 (2010).

29. Britt, W.J., Jarvis, M., Seo, J.Y., Drummond, D. \& Nelson, J. Rapid genetic engineering of human cytomegalovirus by using a lambda phage linear recombination system: demonstration that pp28 (UL99) is essential for production of infectious virus. $J$ Virol 78, 539-543 (2004).

30. Dargan, D.J., et al. Sequential mutations associated with adaptation of human cytomegalovirus to growth in cell culture. $J$ Gen Virol 91, 1535-1546 (2010).

31. Stanton, R.J., et al. Reconstruction of the complete human cytomegalovirus genome in a BAC reveals RL13 to be a potent inhibitor of replication. J Clin Invest 120, 3191-3208 (2010).

32. Lilja, A.E. \& Shenk, T. Efficient replication of rhesus cytomegalovirus variants in multiple rhesus and human cell types. Proc Nat/ Acad Sci U S A 105, 19950-19955 (2008).

33. Wang, D. \& Shenk, T. Human cytomegalovirus virion protein complex required for epithelial and endothelial cell tropism. Proc Natl Acad Sci U S A 102, 18153-18158 (2005).

34. Murrell, I., et al. Genetic Stability of Bacterial Artificial Chromosome-Derived Human Cytomegalovirus during Culture In Vitro. $J$ Virol 90, 3929-3943 (2016).

35. Hansen, S.G., et al. Broadly targeted CD8(+) T cell responses restricted by major histocompatibility complex E. Science 351, 714720 (2016).

36. Jones, K.E., et al. Global trends in emerging infectious diseases. Nature 451, 990-993 (2008).

37. Chang, W.L., Kirchoff, V., Pari, G.S. \& Barry, P.A. Replication of rhesus cytomegalovirus in life-expanded rhesus fibroblasts expressing human telomerase. J Virol Methods 104, 135-146 (2002). 
38. Tischer, B.K., von Einem, J., Kaufer, B. \& Osterrieder, N. Two-step red-mediated recombination for versatile high-efficiency markerless DNA manipulation in Escherichia coli. Biotechniques 40, 191-197 (2006).

39. Langmead, B. \& Salzberg, S.L. Fast gapped-read alignment with Bowtie 2. Nat Methods 9, 357-359 (2012).

40. Milne, I., et al. Using Tablet for visual exploration of second-generation sequencing data. Brief Bioinform 14, 193-202 (2013).

41. Assaf, B.T., et al. Limited dissemination and shedding of the UL128 complex-intact, UL/b'-defective rhesus cytomegalovirus strain 180.92. J Virol 88, 9310-9320 (2014).

42. Marshall, E.E., et al. Enhancing safety of cytomegalovirus-based vaccine vectors by engaging host intrinsic immunity. Sci Transl Med 11(2019).

\section{Supplementary Information}

Supplementary Figure 1 is available in the Supplemental Files section.

\section{Supplementary Figure 1. Example of RFLP analysis of repaired $\mathrm{RhCMV}_{68-1} /$ EBOV-based BACs.}

RFLP analysis of the $\mathrm{RhCMV}_{68-1} /$ EBOV-based BAC in which RL11B was repaired (Step 7 in Table 2). The white dots mark fragments that are present in the parental BAC or the repaired BACs (results of three clones are shown).

Supplementary Table 1. Relative abundance of sense transcripts from $\mathrm{RhCMV}_{68-1} / \mathrm{EBOV} / \mathrm{RL} 11 \mathrm{G}^{-}$coding regions. 


\begin{tabular}{|c|c|c|}
\hline Gene $^{a}$ & Protein $^{\mathrm{b}}$ & $\%$ transcripts ${ }^{c}$ \\
\hline UL146D & chemokine vCXCL7 & 14.99 \\
\hline UL22A & glycoprotein UL22A & 11.91 \\
\hline UL146C & chemokine vCXCL6 & 7.40 \\
\hline RNA4.9 & [long noncoding RNA] & 4.41 \\
\hline UL132 & envelope glycoprotein UL132 & 3.43 \\
\hline EBOV-GP & EBOV-GP & 2.31 \\
\hline UL84 & protein UL84 & 2.21 \\
\hline UL40 & membrane glycoprotein UL40 & 2.00 \\
\hline UL30A & protein UL30A & 1.96 \\
\hline UL99 & myristylated tegument protein & 1.59 \\
\hline UL71 & tegument protein UL51 & 1.47 \\
\hline UL82 & tegument protein pp71 & 1.06 \\
\hline UL80 & capsid maturation protease and scaffold protein & 1.05 \\
\hline UL148 & membrane protein UL148 & 1.03 \\
\hline UL42 & protein UL42 & 1.03 \\
\hline UL48A & small capsid protein & 0.84 \\
\hline UL34 & protein UL34 & 0.83 \\
\hline UL17 & protein UL17 & 0.83 \\
\hline UL26 & tegument protein UL26 & 0.81 \\
\hline UL85 & capsid triplex subunit 2 & 0.74 \\
\hline UL115 & envelope glycoprotein L & 0.71 \\
\hline UL43 & tegument protein UL43 & 0.70 \\
\hline UL122 (exon 3) & regulatory protein IE2 & 0.69 \\
\hline UL128 & envelope protein UL128 & 0.67 \\
\hline UL92 & protein UL92 & 0.67 \\
\hline $\mathrm{O} 25$ & protein $\mathrm{O} 25$ & 0.66 \\
\hline UL94 & tegument protein UL16 & 0.64 \\
\hline UL112 & protein UL112 & 0.63 \\
\hline UL87 & protein UL87 & 0.62 \\
\hline US12 & membrane protein US12 & 0.59 \\
\hline UL32 & tegument protein pp150 & 0.59 \\
\hline UL41A & protein UL41A & 0.57 \\
\hline UL88 & tegument protein UL88 & 0.56 \\
\hline RL11I & membrane protein RL11I & 0.56 \\
\hline UL98 & deoxyribonuclease & 0.54 \\
\hline UL91 & protein UL91 & 0.53 \\
\hline UL45 & ribonucleotide reductase subunit 1 & 0.52 \\
\hline UL78 & envelope protein UL78 & 0.50 \\
\hline UL49 & protein UL49 & 0.50 \\
\hline UL74A & envelope glycoprotein 24 & 0.45 \\
\hline UL144 & membrane glycoprotein UL144 & 0.43 \\
\hline UL111A & interleukin-10 & 0.43 \\
\hline UL46 & capsid triplex subunit 1 & 0.41 \\
\hline UL100 & envelope glycoprotein $\mathrm{M}$ & 0.40 \\
\hline US30 & membrane protein US30 & 0.39 \\
\hline US6C & protein US6C & 0.38 \\
\hline UL14 & membrane protein UL14 & 0.38 \\
\hline UL130 & envelope glycoprotein UL130 & 0.36 \\
\hline UL44 & DNA polymerase processivity subunit & 0.36 \\
\hline UL75 & envelope glycoprotein $\mathrm{H}$ & 0.36 \\
\hline $\mathrm{O} 12$ & protein 012 & 0.35 \\
\hline UL147 & chemokine vCXCL2 & 0.33 \\
\hline US6 & membrane glycoprotein US6 & 0.33 \\
\hline COX2 & prostaglandin G/H synthase 2 & 0.32 \\
\hline UL73 & envelope glycoprotein $\mathrm{N}$ & 0.32 \\
\hline UL38 & protein UL38 & 0.32 \\
\hline US22 & tegument protein US22 & 0.32 \\
\hline UL146B & chemokine vCXCL5 & 0.32 \\
\hline UL103 & tegument protein UL7 & 0.31 \\
\hline UL116 & protein UL116 & 0.30 \\
\hline UL147A & membrane protein UL147A & 0.27 \\
\hline US27A & membrane protein US27A & 0.27 \\
\hline UL53 & nuclear egress lamina protein & 0.27 \\
\hline US27E & membrane protein US27E & 0.26 \\
\hline UL83A & protein UL83A & 0.25 \\
\hline UL123 (exon 3) & regulatory protein IE1 & 0.25 \\
\hline UL146F & chemokine vCXCL9 & 0.25 \\
\hline $\mathrm{O} 19$ & protein O19 & 0.24 \\
\hline UL31 & protein UL31 & 0.24 \\
\hline US17 & membrane protein US17 & 0.23 \\
\hline $\mathrm{O} 13$ & protein 013 & 0.22 \\
\hline
\end{tabular}

Page 16/24 


\begin{tabular}{|c|c|c|}
\hline $\mathrm{O} 24$ & protein $\mathrm{O} 24$ & 0.22 \\
\hline RL11J & membrane protein RL11J & 0.21 \\
\hline UL55 & envelope glycoprotein B & 0.21 \\
\hline $\mathrm{UL} 146 \mathrm{H}$ & chemokine vCXCL11 & 0.21 \\
\hline UL114 & uracil-DNA glycosylase & 0.20 \\
\hline UL145 & protein UL145 & 0.20 \\
\hline UL30 & protein UL30 & 0.20 \\
\hline $\mathrm{O} 21$ & protein $\mathrm{O} 21$ & 0.20 \\
\hline UL86 & major capsid protein & 0.19 \\
\hline UL52 & DNA packaging protein UL32 & 0.19 \\
\hline RS1 & tegument protein TRS1 & 0.19 \\
\hline US18 & membrane protein US18 & 0.18 \\
\hline UL20 & membrane protein UL20 & 0.18 \\
\hline UL33 & envelope glycoprotein UL33 & 0.18 \\
\hline UL131A & envelope protein UL131A & 0.18 \\
\hline UL54 & DNA polymerase catalytic subunit & 0.18 \\
\hline UL25 & tegument protein UL25 & 0.17 \\
\hline UL36 & tegument protein vICA & 0.17 \\
\hline US27B & membrane protein US27B & 0.17 \\
\hline RL1 & protein RL1 & 0.17 \\
\hline $\mathrm{O} 7$ & protein $\mathrm{O} 7$ & 0.17 \\
\hline UL35 & tegument protein UL35 & 0.17 \\
\hline UL141 & membrane glycoprotein UL141 & 0.16 \\
\hline RL11H & membrane protein RL11H & 0.16 \\
\hline UL93 & DNA packaging tegument protein UL17 & 0.16 \\
\hline UL21A & protein UL21A & 0.15 \\
\hline O9 & protein 09 & 0.15 \\
\hline RL11A & membrane protein RL11A & 0.15 \\
\hline US29 & membrane protein US29 & 0.15 \\
\hline $\mathrm{O} 23$ & protein $\mathrm{O} 23$ & 0.14 \\
\hline US32 & protein US32 & 0.14 \\
\hline UL50 & nuclear egress membrane protein & 0.13 \\
\hline UL69 & multifunctional expression regulator & 0.13 \\
\hline UL13 & protein UL13 & 0.13 \\
\hline US12E & membrane protein US12E & 0.13 \\
\hline US12 & membrane protein US12A & 0.13 \\
\hline UL117 & protein UL117 & 0.12 \\
\hline UL57 & single-stranded DNA-binding protein & 0.12 \\
\hline UL37 & envelope glycoprotein UL37 & 0.11 \\
\hline $\mathrm{O} 14$ & protein 014 & 0.11 \\
\hline UL23 & tegument protein UL23 & 0.11 \\
\hline UL72 & deoxyuridine triphosphatase & 0.11 \\
\hline US3 & membrane glycoprotein US3 & 0.11 \\
\hline US26 & protein US26 & 0.10 \\
\hline UL119 & membrane glycoprotein UL119 & 0.10 \\
\hline US27D & membrane protein US27D & 0.10 \\
\hline UL89 & DNA packaging terminase subunit 1 & 0.10 \\
\hline US28 & envelope protein US28 & 0.10 \\
\hline UL77 & DNA packaging tegument protein UL25 & 0.10 \\
\hline RL11T & membrane protein RL11T & 0.09 \\
\hline UL104 & capsid portal protein & 0.09 \\
\hline US11 & membrane glycoprotein US11 & 0.08 \\
\hline UL27 & protein UL27 & 0.08 \\
\hline UL105 & helicase-primase helicase subunit & 0.08 \\
\hline US31 & protein US31 & 0.07 \\
\hline US20 & membrane protein US20 & 0.07 \\
\hline US6A & membrane glycoprotein US6A & 0.07 \\
\hline UL97 & tegument serine/threonine protein kinase & 0.06 \\
\hline US1 & protein US1 & 0.06 \\
\hline UL124 & membrane protein UL124 & 0.05 \\
\hline UL19 & protein UL19 & 0.05 \\
\hline O15 & protein $\mathrm{O} 15$ & 0.05 \\
\hline UL56 & DNA packaging terminase subunit 2 & 0.05 \\
\hline US19 & membrane protein US19 & 0.05 \\
\hline RL11G & membrane protein RL11G & 0.05 \\
\hline $\mathrm{O} 22$ & protein $\mathrm{O} 22$ & 0.05 \\
\hline UL79 & protein UL79 & 0.05 \\
\hline O10 & protein $\mathrm{O} 10$ & 0.05 \\
\hline UL51 & DNA packaging protein UL33 & 0.05 \\
\hline US2 & membrane glycoprotein US2 & 0.04 \\
\hline UL48 & large tegument protein & 0.04 \\
\hline US6B & membrane glycoprotein US6B & 0.04 \\
\hline
\end{tabular}

Page 17/24 


\begin{tabular}{|c|c|c|}
\hline UL76 & nuclear protein UL24 & 0.04 \\
\hline $\mathrm{O} 4$ & protein $\mathrm{O} 4$ & 0.04 \\
\hline UL96 & tegument protein UL14 & 0.04 \\
\hline UL24 & tegument protein UL24 & 0.04 \\
\hline UL29 & protein UL29 & 0.04 \\
\hline UL47 & tegument protein UL37 & 0.03 \\
\hline UL74 & envelope glycoprotein $\mathrm{O}$ & 0.03 \\
\hline UL102 & helicase-primase subunit & 0.03 \\
\hline US12B & membrane protein US12B & 0.03 \\
\hline O16 & protein 016 & 0.02 \\
\hline US23 & protein US23 & 0.02 \\
\hline US21 & membrane protein US21 & 0.02 \\
\hline O11 & protein 011 & 0.02 \\
\hline UL95 & protein UL95 & 0.02 \\
\hline US12C & membrane protein US12C & 0.02 \\
\hline O8 & protein 08 & 0.02 \\
\hline US12D & membrane protein US12D & 0.02 \\
\hline UL70 & helicase-primase primase subunit & 0.02 \\
\hline $\mathrm{O} 17$ & protein 017 & 0.01 \\
\hline $\mathrm{O} 6$ & protein $\mathrm{O} 6$ & 0.01 \\
\hline RL11S & membrane protein RL11S & 0.01 \\
\hline $\mathrm{O} 1$ & membrane protein $\mathrm{O} 1$ & 0.01 \\
\hline UL120 & membrane protein UL120 & 0.01 \\
\hline UL121 & membrane protein UL121 & 0.01 \\
\hline US24 & tegument protein US24 & 0.01 \\
\hline $\mathrm{O} 20$ & membrane protein $\mathrm{O} 20$ & 0.01 \\
\hline $\mathrm{O5}$ & protein $\mathrm{O5}$ & 0.01 \\
\hline RL11F & membrane protein RL11F & 0.00 \\
\hline $\mathrm{O} 3$ & protein $\mathrm{O} 3$ & 0.00 \\
\hline RL11R & membrane protein RL11R & 0.00 \\
\hline RL11Q & membrane protein RL11Q & 0.00 \\
\hline RL11K & membrane protein RL11K & 0.00 \\
\hline $\mathrm{O} 18$ & protein 018 & 0.00 \\
\hline RL11E & membrane protein RL11E & 0.00 \\
\hline RL11P & membrane protein RL11P & 0.00 \\
\hline RL11B & membrane protein RL11B & 0.00 \\
\hline RL11D & membrane protein RL11D & 0.00 \\
\hline RL11C & membrane protein RL11C & 0.00 \\
\hline RL11O & membrane protein RL11O & 0.00 \\
\hline RL11L & membrane protein RL11L & 0.00 \\
\hline RL11M & membrane protein RL11M & 0.00 \\
\hline RL11N & membrane protein RL11N & 0.00 \\
\hline
\end{tabular}

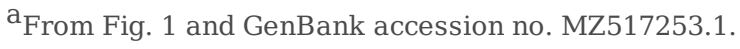

$\mathrm{b}_{\text {From GenBank accession no. MZ517253.1. }}$

${ }^{\mathrm{C}}$ Number of sense transcripts from individual coding regions as a percentage of the number of sense and antisense transcripts from all coding regions. Ranked from the greatest number of transcripts to the least. Accuracy is limited by several factors. First, values for small coding regions may be depressed because of reduced mapping of reads to their ends. For example, this may lead to an underestimate of the levels of expression of UL146D and UL22A (first and second, respectively, in the list). Second, expression of upstream coding regions in a family of overlapping mRNAs sharing a $3^{\prime}$-end will enhance the apparent level of expression of downstream coding regions. For example, this may lead to an overestimate of the level of expression of UL146D (first in the list), which is probably 3'-coterminal with UL146C (third in the list); this would make UL22A first in the list. Third, a proportion of antisense transcripts may have been generated from overlapping noncoding regions of sense transcripts from adjacent genes. For example, UL89 (exon 1) is overlapped by the 3'-end of the more highly expressed UL94 on the opposite strand. This factor may also lead to an overestimate of the overall proportion of antisense trancripts (6.84\%).

\section{Supplementary Table 2. Primers used for repair of ORFs in $\mathrm{RhCMV}_{68-1} / \mathrm{EBOV}$}




\begin{tabular}{|c|c|c|}
\hline Name & Sequence & Purpose \\
\hline $\begin{array}{l}\text { Rh157.4 } \\
\text { Rh157.5 } \\
\text { Rh157.6 } \\
\text { Forward }\end{array}$ & GTACGATACTGTACGGTTGTTGCATATTTTGAAGTCATAGCAGTCCTGTG TAGGGATAACAGGGTAATCGATTT & \multirow{2}{*}{$\begin{array}{l}\text { Introduction } \\
\text { of I-SceI } \\
\text { sequences } \\
\text { and a } \\
\text { kanamycin } \\
\text { resistance } \\
\text { gene in the } \\
\text { shuttle } \\
\text { plasmid } \\
\text { containing } \\
\text { UL124 to } \\
\text { UL132 }\end{array}$} \\
\hline $\begin{array}{l}\text { Rh157.4 } \\
\text { Rh157.5 } \\
\text { Rh157.6 } \\
\text { Reverse }\end{array}$ & GTAGCCAGTGTTACAACCAATTAACC & \\
\hline $\begin{array}{l}\text { Rh157.4 } \\
\text { Rh157.6 } \\
\text { Forward }\end{array}$ & AGCCGTCTACATACGGACACCACCTTTATAAGTGCTTCTACAGTGGATTTATGTGCTTAACAATACGGCAAGTAAGCCTG & \multirow{2}{*}{$\begin{array}{l}\text { Amplification } \\
\text { of fragment } \\
\text { containing } \\
\text { UL130 to } \\
\text { UL131A and } \\
\text { introduction } \\
\text { of a } \\
\text { kanamycin } \\
\text { resistance } \\
\text { gene }\end{array}$} \\
\hline $\begin{array}{l}\text { Rh157.4 } \\
\text { Rh157.6 } \\
\text { Reverse }\end{array}$ & TCCCTACTATAAATAACGTGCTG & \\
\hline $\begin{array}{l}\text { Rh157.5 } \\
\text { Forward }\end{array}$ & AGCCGTCTACATACGGACAC & \multirow{2}{*}{$\begin{array}{l}\text { Amplification } \\
\text { of fragment } \\
\text { containing } \\
\text { UL128 and } \\
\text { introduction } \\
\text { of a } \\
\text { kanamycin } \\
\text { resistance } \\
\text { gene }\end{array}$} \\
\hline $\begin{array}{l}\text { Rh157.5 } \\
\text { Reverse }\end{array}$ & TGTTTAGGCGGCATCCTTC & \\
\hline $\begin{array}{l}\text { Rh13.1 } \\
\text { Forward }\end{array}$ & AAACAGTGCCATGACTAAGTATACGTGCTTCAGATCGATGTCTGCCTGCGTAGGGATAACAGGGTAATCGATTT & \multirow{2}{*}{$\begin{array}{l}\text { Removal of } \\
\text { RL11G and } \\
\text { introduction } \\
\text { of a } \\
\text { kanamycin } \\
\text { resistance } \\
\text { gene }\end{array}$} \\
\hline $\begin{array}{l}\text { Rh13.1 } \\
\text { Reverse }\end{array}$ & AAACTCGCAATGGCTTCTCAGGGTAGCTTGTCGATCCGCGCGCACGTTCGGCCAGTGTTACAACCAATTAACC & \\
\hline
\end{tabular}

\section{Figures}




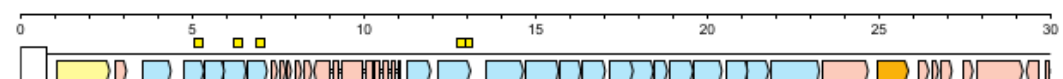

$\begin{array}{lllllllll}\text { RL1 RL11A } & \text { RL11E 06 } & \text { COX2 } & \text { RL11F } & \text { RL11H } & \text { RL11K RL11N } & \text { RL11Q } & \text { UL13 UL14 UL17 } & \text { UL21A }\end{array}$

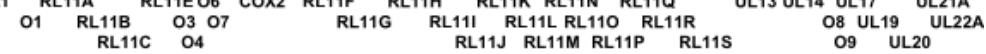
RL110 05

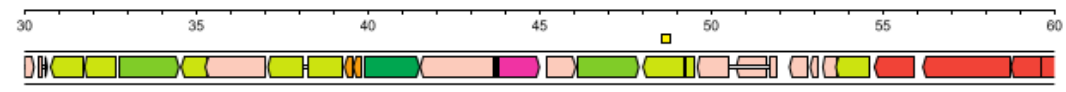

\begin{tabular}{cccccccccc}
\hline UL23 & UL25 & UL27 & UL30 & UL32 & UL33 & UL35 UL36 UL37 & UL40 UL43 & UL45 UL46
\end{tabular}

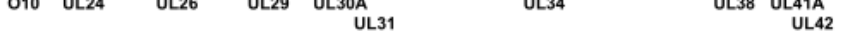

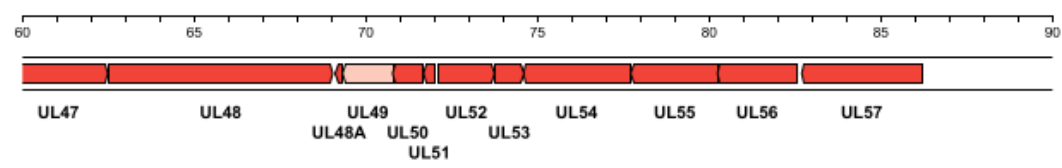

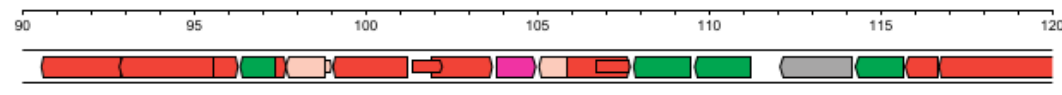

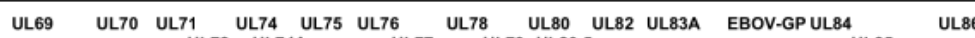
$\begin{array}{lll}\text { UL72 UL734A UL77 UL80.5 } & \text { UL79 }\end{array}$

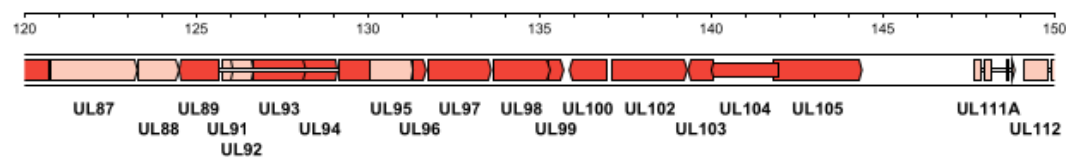

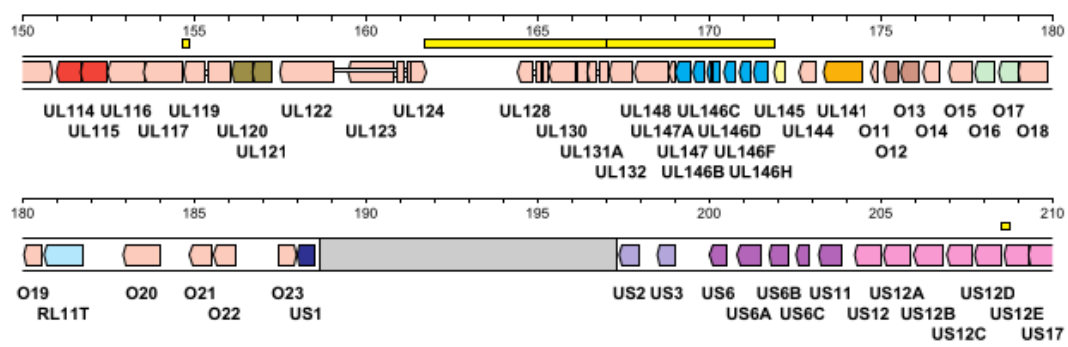

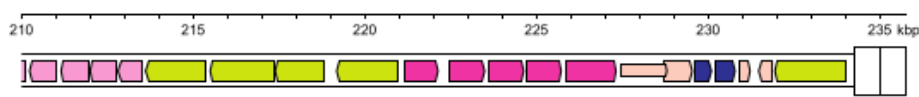

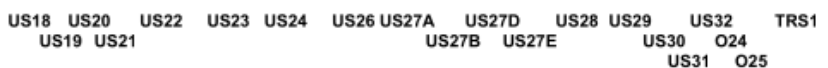

$\begin{array}{llllll}\square \text { CXCL } & \square \text { RL1 } & \square \text { UL25 } & \square \text { US1 } & \square \text { US12 } & \square \text { O16 } \\ \text { DURP } & \square \text { RL11 } & \square \text { UL30 } & \square \text { US2 } & \square \text { US22 } & \square \text { Other noncore ORFs } \\ \square \text { GPCR } & \square \text { UL14 } & \square \text { UL120 } & \square \text { US6 } & \square \text { O13 } & \square \text { Core ORFs }\end{array}$

\section{Figure 1}

Genetic map of RhCMV68-1/EBOV/RL11G+ BAC. The circular sequence is depicted in linear form, starting at the left end of the viral genome with one copy of the terminal direct repeat (TR), proceeding through the unique region (U), and ending with two more copies of TR. The copies of TR are shown in a thicker format than U. Protein-coding ORFs are indicated by coloured open arrows grouped according to the key at the foot to indicate gene families, other non-core genes that are not conserved among herpesviruses and core genes that are conserved among herpesviruses. Introns connecting protein-coding regions are shown as narrow white bars. UL72 is both a core gene and member of the DURP gene family and is shown as the latter. The BAC vector is shown by the grey-shaded region between US1 and US2. The EBOV-GP ORF encoding a V5-tagged EBOV spike glycoprotein is also grey-shaded and replaced US83B. The locations of small-scale and large-scale repairs (see Table 2) are marked above the genome by yellow squares and bars, respectively. 


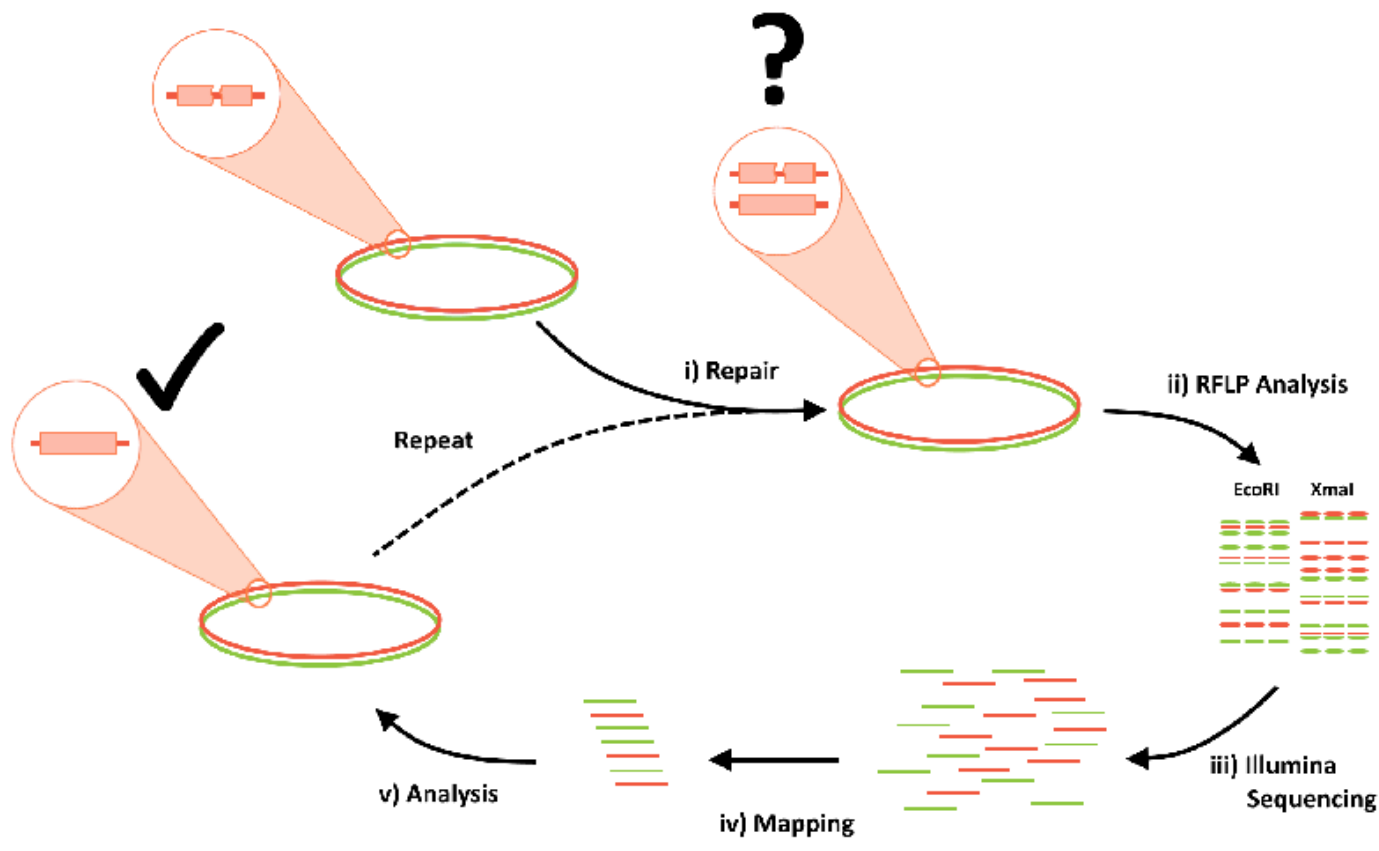

\section{Figure 2}

Schematic showing the HHi-FiVe pipeline. i) Lambda Red recombination and en passant mutagenesis are used to repair individual ORFs in the BAC, ii) the repaired BAC is screened by using RFLP, and then iii) Illumina sequencing, iv) read mapping v) accompanied by analysis are used to confirm the intended repair and the absence of off-site mutations. The process is repeated until all repairs are made. 


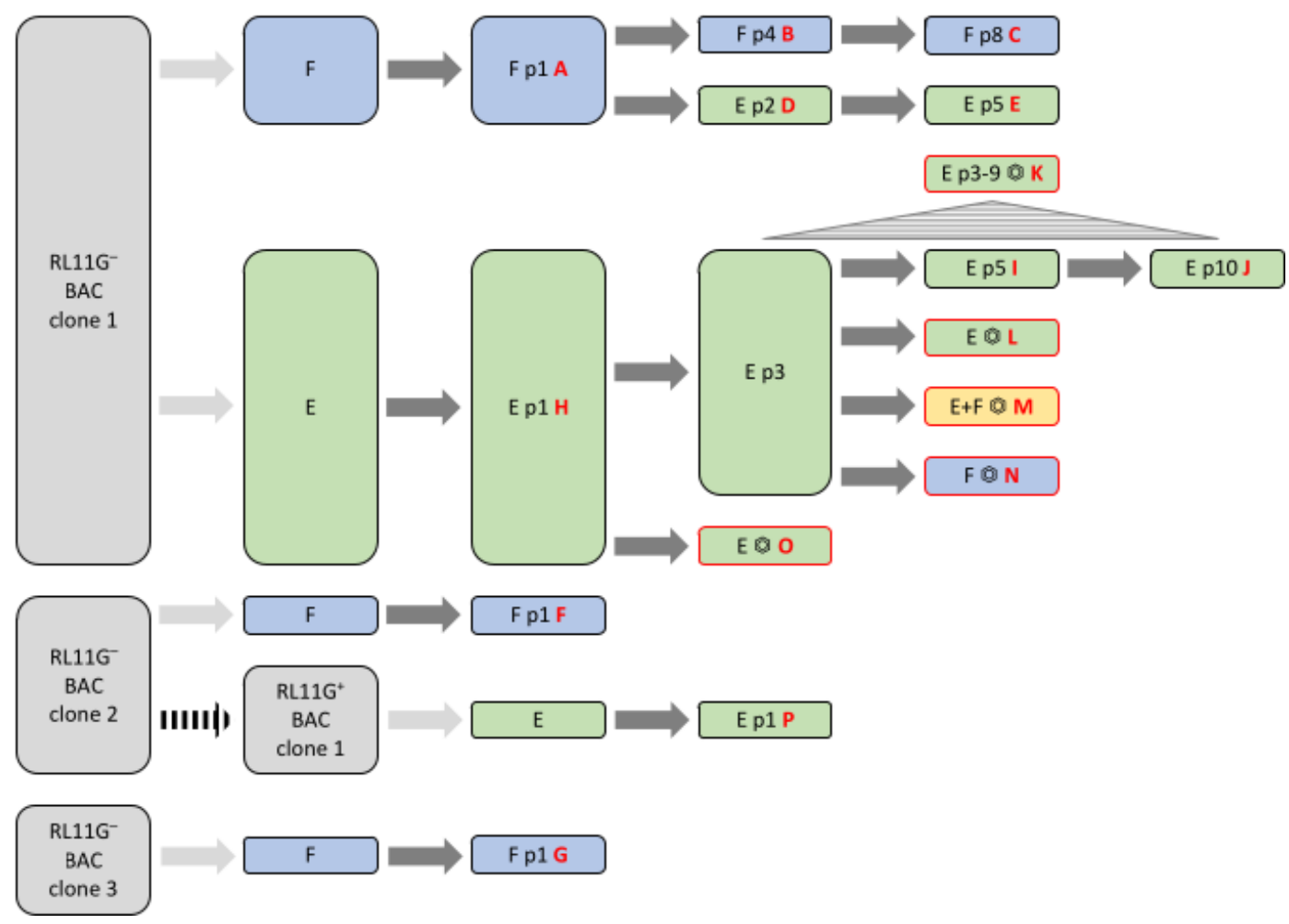

Figure 3

Reconstitution and passaging of viruses for sequencing. Clones of RhCMV68-1/EBOV/RL11G- BAC and RhCMV68-1/EBOV/RL11G+ BAC (denoted RL11G- BAC and RL11G+ BAC, respectively; shaded grey) were transfected into Telo-RF (F; shaded blue) or hTERT RPE1 ( $E$; shaded green) cells or a 1:1 mixture of these cells $(E+F$; shaded orange). The transfected cells were passaged further ( $p$, passage number), and, in some instances, virus stocks $(\mathbb{\nabla})$ were made. The hatched triangle indicates that a stock was made from a mixture of yields from several passages. Hatched arrows indicate recombineering, light grey arrows indicate transfection, and dark grey arrows indicate passaging and expansion. Samples A-P (red font) were sequenced from DNA isolated from infected cells (black border of the rounded rectangles) or infected cell supernatant (red border of the rounded rectangles). 


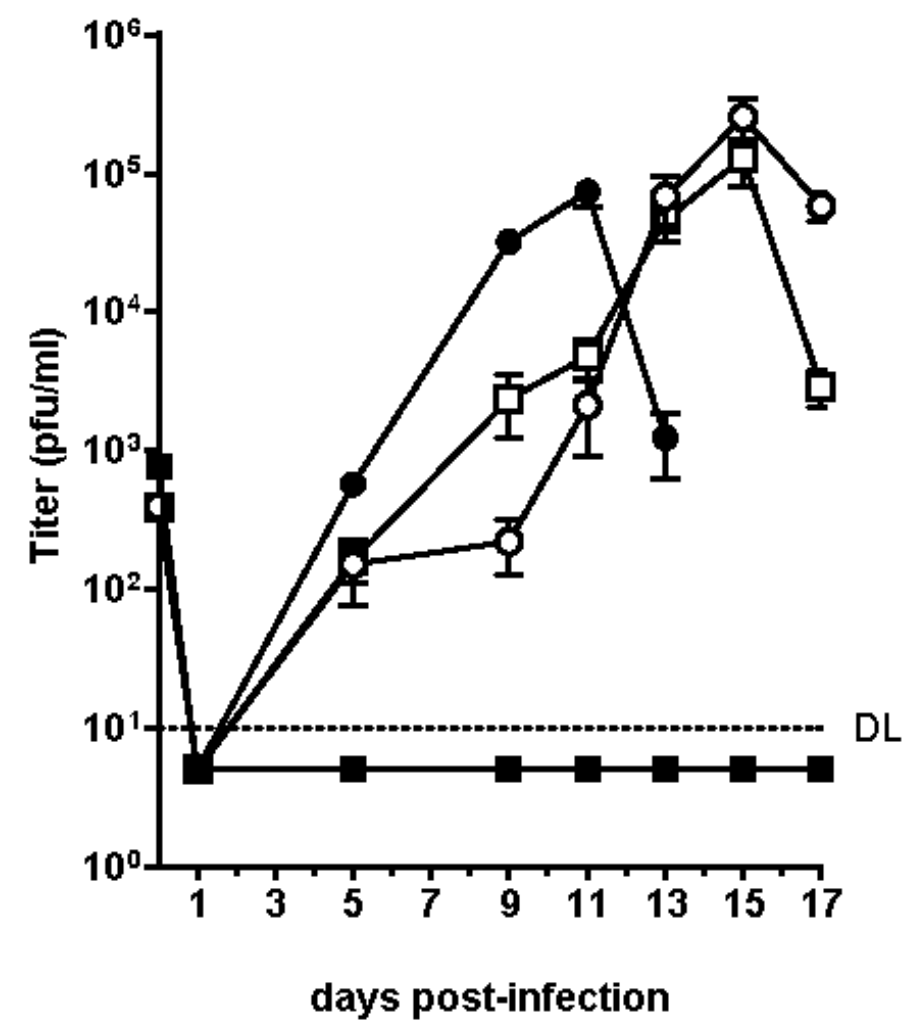

Figure 4

Cellular tropism of RhCMV68-1/EBOV/RL11G- compared to parental RhCMV68-1/EBOV-GP. Multi-step growth analysis was conducted by infecting Telo-RF (circles) or hTERT RPE-1 (squares) cells at a MOI of 0.2 PFU/cell with the reconstituted viruses RhCMV68-1/EBOVGP (closed symbols) or RhCMV68-1/EBOV/RL11G- (open symbols). Supernatant was collected at the indicated d p.i. and titrated using a plaque assay. Titers are shown as \pm SEM. DL, detection limit. 
A

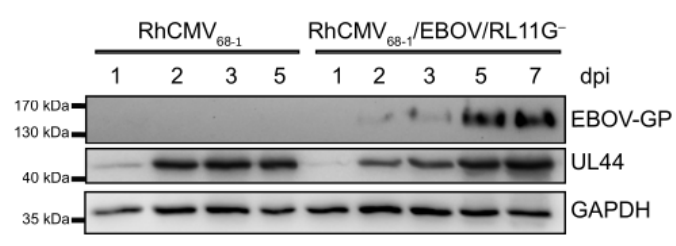

B

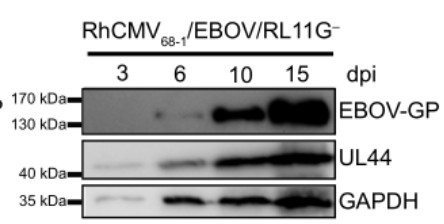

\section{Figure 5}

EBOV-GP expression of reconstituted viruses. A) Telo-RF cells were infected at a MOI of 0.2 PFU/cell with either RhCMV68-1 or RhCMV68-1/EBOV/RL11G-. B) hTERT RPE-1 cells were infected at a MOI of 0.4 PFU/cell with RhCMV68-1/EBOV/RL11G-. In both experiments, cell lysates were collected at the indicated d p.i and analyzed by immunoblotting. EBOV-GP was detected by using an EBOV GP-specific mAb. An antibody against the RhCMV UL44 protein was used as a viral infection control, and a mAb against cellular GAPDH was used as a cellular protein loading control.

\section{Supplementary Files}

This is a list of supplementary files associated with this preprint. Click to download.

- RL11Brepaired.pdf

- UCDavisPREEMPTConsortiumAuthorListSubmitted190ct21.docx 